\title{
Male circumcision and common sexually transmissible diseases in a developed nation setting
}

B Donovan, I Bassett, N J Bodsworth

\begin{abstract}
Objective-To determine whether the circumcision status of men affected their likelihood of acquiring sexually transmissible diseases (STDs).

Design-A cross-sectional study employing an anonymous questionnaire, clinical examination and type specific serology for herpes simplex virus type 2 (HSV-2). Setting-A public STD clinic in Sydney, Australia.

Subjects-300 consecutive heterosexual male patients.

Main outcome measures-Associations between circumcision status and past or present diagnoses of STDs including HSV-2 serology and clinical pattern of genital herpes.
\end{abstract}

Results-185 (62\%) of the men were circumcised and they reported similar ages, education levels and lifetime partner numbers as men who were uncircumcised. There were no significant associations between the presence or absence of the male prepuce and the number diagnosed with genital herpes, genital warts and non-gonococcal urethritis. Men who were uncircumcised were no more likely to be seropositive for $\mathrm{HSV}-2$ and reported symptomatic genital herpes outbreaks of the same frequency and severity as men who were circumcised. Gonorrhoea, syphilis and acute hepatitis $B$ were reported too infrequently to reliably exclude any association with circumcision status. Human immunodeficiency virus infection (rare among heterosexual men in the clinic) was an exclusion criterion.

Conclusions-From the findings of this study, circumcision of men has no significant effect on the incidence of common STDs in this developed nation setting. However, these findings may not necessarily extend to other setting where hygiene is poorer and the spectrum of common STDs is different.

Sydney Sexual Health Centre, Sydney Hospital, Sydney B Donovan I Bassett

N J Bodsworth

Address correspondence to: A/Prof Basil Donovan, Sydney Sexual Health Centre, Sydney Hospital, GPO Box 1614, Sydney, NSW, 2001, Australia.

Accepted for publication 4 May 1994
(Genitourin Med 1994;70:317-320)

\section{Introduction}

It has been suggested that uncircumcised men are at higher risk of certain sexually transmissible diseases (STDs), in particular genital herpes, ${ }^{12}$ gonorrhoea, ${ }^{1}$ syphilis, ${ }^{1}$ human immunodeficiency virus type 1 (HIV-1) infection, ${ }^{3}$ candidiasis $^{12}$ and chancroid. ${ }^{3}$ The evi- dence for male circumcision protecting against most STDs is tentative ${ }^{4}$ but is strong for chancroid and candidal balanoposthitis (though not necessarily subclinical yeast infection ${ }^{5}$ ). In some populations where chancroid and syphilis may be the common causes of genital ulcers, these ulcers and the uncircumcised state of the men (both independently and synergistically) appear to be major risk factors for the female to male sexual transmission of HIV-1. ${ }^{3}$

The uncircumcised penis is hypothetically at increased risk of STDs because of larger surface area, thinner epidermal barrier, more opportunity for epithelial microtrauma and the warm, moist niche under the foreskin favouring the persistence of fastidious microorganisms. However, none of these hypotheses has been proven.

We sought to determine any effect the presence of a male foreskin may exert on the acquisition of common STDs by heterosexual men attending an STD clinic and also its effect on the clinical manifestations of herpes simples virus type 2 (HSV-2) infection.

\section{Subjects and methods}

A sample size of over 270 was calculated to determine a two-fold risk of serological evidence of HSV-2 for uncircumcised men with $80 \%$ power at the $5 \%$ level. However, this calculation was based on an expected HSV-2 seroprevalence of about $30 \%$ for heterosexual men detected in a 1985 survey at the same clinic (AL Cunningham; unpublished data).

The subjects were 300 consecutive heterosexual male patients who saw a particular clinician (IB) and required venepuncture for any other purpose at the Sydney Sexual Health (previously STD) Centre, Sydney Hospital, between December 1990 and May 1991. Over $95 \%$ of the men were Caucasian with the bulk of the remainder of Asian origin. The subjects were representative of the general clinical load of exclusively heterosexual men at the Centre: their reasons for attendance or diagnosis at the time of consultation are outlined in table 1. HIV-1 infection is rare among heterosexual men attending the Centre ${ }^{6}$ and, as HIV-1 infection may alter the natural history of other STDs, it was an exclusion criterion. Homosexually active men were also excluded because anal infections could have confused the objectives of the study. The aims of the study were explained to all subjects and signed informed consent obtained. There were no refusals. 
Table 1 Current diagnoses in 300 consecutive heterosexual men attending an STD clinic

\begin{tabular}{lcc}
\hline & Number & Percent \\
\hline Screening only (asymptomatic) & 168 & $56 \cdot 0$ \\
Nongonococcal urethritis & 57 & $19 \cdot 0$ \\
Genital warts & 26 & $8 \cdot 7$ \\
Gonorrhoea & 1 & $0 \cdot 3$ \\
Genital herpes (clinical diagnosis) & 4 & $1 \cdot 3$ \\
$\quad$ initial episode & 10 & $3 \cdot 3$ \\
recurrence & 0 & 0 \\
Syphilis & 0 & 0 \\
Chancroid & 3 & $1 \cdot 0$ \\
Other genital ulcer & 31 & $10 \cdot 3$ \\
Other (non-infectious) condition & 300 & 100 \\
Total & &
\end{tabular}

A data collection form with an anonymous identifier code was completed by the clinician and an extra five millitres of blood was collected for this study. The data collected included age, level of education, circumcision status (confirmed by physical examination), past history of genital herpes or symptoms suggestive of genital herpes (undiagnosed genital ulcer or recurrent genital lesions/itches), nongonococcal urethritis (NGU), genital warts, urethral gonorrhoea, syphilis and acute hepatitis $B$, as well as reported lifetime number of sexual partners (women with whom they had had vaginal intercourse). For the analysis, current and past diagnoses of STDs were combined for each subject. All STDs had been diagnosed by a physician, mostly at the same clinic. The diagnosis of genital herpes was by cell culture except for the current visit where the diagnosis was on clinical criteria (the delinked anonymous study design precluded incorporating current HSV culture results). Similarly urethral gonorrhoea was diagnosed by culture except for the current visit where the diagnosis was based on clinical findings plus characteristic gram negative intracellular diplococci on a urethral smear. NGU was diagnosed by clinical picture (discharge/dysuria) and microscopy of a distal urethral smear ( 5 or more polymorphs

Table 2 Circumcision status and demographic, behavioural and disease variables of 300 heterosexual men

\begin{tabular}{|c|c|c|c|}
\hline & $\begin{array}{l}\text { Circumcised } \\
n=185\end{array}$ & $\begin{array}{l}\text { Uncircumcised } \\
n=115\end{array}$ & $\begin{array}{l}\text { Odds ratio } \\
(95 \% \mathrm{CI})^{*}\end{array}$ \\
\hline $\begin{array}{l}\text { Mean age in years } \\
\text { (range) }\end{array}$ & $\begin{array}{l}31 \cdot 1 \\
(20-60)\end{array}$ & $\begin{array}{l}31 \cdot 9 \\
(18-69)\end{array}$ & - \\
\hline $\begin{array}{l}\text { Median lifetime sexual partners } \\
\text { (range) }\end{array}$ & & $\begin{array}{l}20 \\
(2-300)\end{array}$ & - \\
\hline Percent who finished high school & 84.9 & $88 \cdot 7$ & \multirow{3}{*}{$\begin{array}{l}0.71 \\
(0.33-1.52) \\
0.97 \\
(0.59-1.59) \\
0.87 \\
(0.51-1.59)\end{array}$} \\
\hline Percent with any tertiary education & $56 \cdot 7$ & $56 \cdot 5$ & \\
\hline Percent anti-HSV-2 positive & $62 \cdot 2$ & $68 \cdot 7$ & \\
\hline $\begin{array}{l}\text { Percent with a history of: } \\
\text { Genital herpes }\end{array}$ & $14 \cdot 8$ & $17 \cdot 9$ & $\begin{array}{l}0.78 \\
(0 \cdot 39-1 \cdot 54)\end{array}$ \\
\hline $\begin{array}{l}\text { Undiagnosed genital ulcer(s) } \\
\text { or recurrent itch }\end{array}$ & $8 \cdot 6$ & $4 \cdot 3$ & \multirow{6}{*}{$\begin{array}{l}2 \cdot 08 \\
(0 \cdot 70-7 \cdot 47) \\
0 \cdot 92 \\
(0 \cdot 47-1 \cdot 79) \\
0 \cdot 85 \\
(0 \cdot 52-1 \cdot 39) \\
0 \cdot 73 \\
(0 \cdot 25-2 \cdot 14) \\
1 \cdot 25 \\
(0 \cdot 06-7 \cdot 41) \\
0 \cdot 62 \\
(0 \cdot 08-4 \cdot 68)\end{array}$} \\
\hline Genital warts & $16 \cdot 2$ & $17 \cdot 4$ & \\
\hline Non-gonococcal urethritis & $43 \cdot 8$ & $47 \cdot 8$ & \\
\hline Gonorrhoea & $10 \cdot 3$ & $7 \cdot 0$ & \\
\hline Syphilis & $1 \cdot 1$ & 0.9 & \\
\hline Acute hepatitis B & $1 \cdot 6$ & $2 \cdot 6$ & \\
\hline
\end{tabular}

«Student's $t$ test with 2-tail probability, 95\% CI $=95 \%$ confidence intervals. All p values were $>0 \cdot 1$. per oil immersion field). Genital warts were a clinical diagnosis. All syphilis cases required confirmation by specific treponemal serology (Treponema pallidum haemaglutination assay and fluorescent treponemal antibody test). The diagnosis of acute hepatitis $B$ required both an acute hepatitic illness and laboratory confirmation.

Those subjects who had a history of genital herpes were asked to grade the severity of their initial episode ("mild", "moderate", or "severe"), and estimate the number, and similarly grade the severity of any recurrences in the previous 12 months.

The serological analyses for HSV were performed at the Virology Department Centre for Infectious Diseases and Microbiology, Westmead Hospital in Sydney on an anonymous and blinded basis. As described elsewhere, ${ }^{7}$ sera were screened for total HSV antibody by a complement fixing antibody (HSV-CFA) test. Positive specimens on HSV-CFA were then subject to an indirect IgG enzyme immune assay (EIA) specific to the $92 \mathrm{kDa}$ HSV-2 glycoprotein G (gG-2). ${ }^{7}$ All 15 randomly selected sera that were positive for HSV-2 by EIA testing were confirmed by Western blot.

\section{Results}

One hundred and eighty five $(61 \cdot 7 \%)$ of the men were circumcised and $115(38.3 \%)$ were not: this was not age dependant (table 2 ). The associations between male circumcision status and demographic, behavioural and STD variables of the study group are summarised in table 2. None of these variables approached significance at the $5 \%$ level. Though gonorrhoea, syphilis and acute hepatitis B were reported too infrequently to determine any association with the subjects' circumcision status, histories of genital herpes, serological evidence of HSV-2 infection, genital warts and NGU were common and no distinct trends emerged.

Table 3 Circumcision status and self-reported clinical features of 46 men with symptomatic genital herpes

\begin{tabular}{|c|c|c|c|}
\hline & $\begin{array}{l}\text { Circumcised } \\
n=26\end{array}$ & $\begin{array}{l}\text { Uncircumcised } \\
n=20\end{array}$ & $p$ \\
\hline $\begin{array}{l}\text { Years since initial } \\
\text { HSV episode } \\
\text { mean }(95 \% \mathrm{CI})\end{array}$ & $\begin{array}{l}6 \cdot 7 \\
(4 \cdot 9-8 \cdot 4)\end{array}$ & $\begin{array}{l}5 \cdot 3 \\
(3 \cdot 3-7 \cdot 2)\end{array}$ & $0.30 \dagger$ \\
\hline $\begin{array}{l}\text { Severity of initial } \\
\text { HSV episode }\end{array}$ & & & \\
\hline $\begin{array}{l}\% \text { mild } \\
\% \text { moderate } \\
\% \text { severe }\end{array}$ & $\begin{array}{l}38 \cdot 5 \\
42 \cdot 3 \\
19 \cdot 2\end{array}$ & $\begin{array}{l}40 \cdot 0 \\
25 \cdot 0 \\
35 \cdot 0\end{array}$ & $0.36 \ddagger$ \\
\hline $\begin{array}{l}\text { Percent with HSV lesion } \\
\text { recurrence in previous } \\
12 \text { months }\end{array}$ & $84 \cdot 6$ & $85 \cdot 0$ & $1.00 \$$ \\
\hline $\begin{array}{l}\text { Mean number of HSV } \\
\text { lesion recurrence in } \\
\text { previous } 12 \text { months } \\
(95 \% \mathrm{CI})\end{array}$ & $\begin{array}{l}4 \cdot 5 \\
(3 \cdot 6-5 \cdot 4)\end{array}$ & $\begin{array}{l}4 \cdot 1 \\
(3 \cdot 0-5 \cdot 2)\end{array}$ & $0.78 \dagger$ \\
\hline $\begin{array}{l}\text { Severity of HSV lesion } \\
\text { recurrence in previous } \\
12 \text { months }^{\star}\end{array}$ & & & \\
\hline $\begin{array}{l}\% \text { mild } \\
\% \text { moderate } \\
\% \text { severe }\end{array}$ & $\begin{array}{l}81 \cdot 8 \\
18 \cdot 2 \\
0\end{array}$ & $\begin{array}{l}76 \cdot 5 \\
23 \cdot 5 \\
0\end{array}$ & 0.715 \\
\hline
\end{tabular}

$95 \% \mathrm{CI}=$ confidence interval, * Of subjects who reported recurrences; †Students' $t$ test, $\ddagger$ chi $^{2}=2.06$ (2df), §Fisher's exact method. 
Circumcised and uncircumcised men with previously diagnosed genital herpes reported a similar duration since the initial episode and similar frequency and severity of recurrences in the preceding 12 months (table 3 ). While there was a trend for more uncircumcised men to describe their initial genital herpes episode as severe and for circumcised men to describe it as moderate the difference was not significant.

\section{Discussion}

In this clinic-based prospectively collected survey we found no association between male circumcision status and STDs that are common in our population. Perhaps importantly, our study group was relatively racially homogeneous, lack of circumcision was not a marker of lower socioeconomic status (using the index of education level; table 2), and we controlled for a major parameter of sexual behaviour (lifetime number of sexual partners).

We did not investigate the relationship between the presence of a prepuce and candidal balanoposthitis as we regard the causal relationship as proven. Lack of circumcision is probably also a risk factor for chancroid ${ }^{3}$ but this condition was rare in our population. Similarly syphilis, acute hepatitis B and gonorrhoea were so uncommon among heterosexual men attending our clinic that we were unable to exclude any potential association. HIV-1 infection was an exclusion criterion for the study.

Symptomatic genital herpes and serological evidence of HSV-2 infection were both common in our population. We previously reported on the risk factors for HSV-2 seropositivity in this study group. ${ }^{8}$ On multivariate analysis the risk factors for $\mathrm{HSV}-2$ infection were lifetime number of sexual partners, lower level of education and (marginally) a history of sexual contact with a women with genital herpes. ${ }^{8}$ In the present analysis, circumcision status did not correlate with a history of genital herpes, recurrent genital ulcers or itches (which might have represented undiagnosed herpes), or serological evidence of HSV-2 infection. As an unexpectedly high proportion (two thirds) of our study group were HSV-2 seropositive it would not have been possible to demonstrate a two-fold protective effect for circumcision. Nevertheless no trend toward protection was apparent (table 2).

A previous Australian study which relied on the culture diagnosis of genital herpes did find a correlation between symptomatic genital herpes and lack of circumcision. ${ }^{1}$ However this study did not quantify sexual partner numbers or other parameters of risk. Another possible explanation for this finding in the previous study might have been that men with intact foreskins harbouring $\mathrm{HSV}-2$ may be more symptomatic and thus be more likely to present to a clinic. However, we found that men who were HSV-2 seropositive were no more symptomatic than circumcised men, nor were their lesion recurrences significantly more frequent or severe. As only a limited number of our study subjects were symptomatic, a larger study would be needed to exclude the possibility that uncircumcised men suffer more severe initial episodes of genital herpes.

Previous studies of the effect of circumcision status on genital warts have produced conflicting results. In more heterogeneous populations lack of circumcision has variously been reported as making symptomatic genital warts both more ${ }^{110}$ and less ${ }^{11}$ common. We found it exerted no effect. One retrospective study found that circumcision status affected the distribution of warts on the penis. Uncircumcised men were more likely to present with distal lesions and circumcised men with proximal lesions on the penis. ${ }^{12} \mathrm{We}$ did not investigate this issue. We are unaware of any study to date that has attempted to correlate circumcision status with subclinical HPV infection.

We determined no association between circumcision status and a history of NGU or gonorrhoea. In the case of gonorrhoea this may have been because this was uncommon in our population: the slight trend was for the presence of a foreskin to be "protective". A previous large retrospective American study found no association between gonococcal urethritis and circumcision status. ${ }^{13}$ In the same American study it was found that circumcised men were 1.65 times more likely to present with NGU than uncircumcised men $(95 \% \mathrm{CI}$; $1 \cdot 37-2 \cdot 00) .{ }^{13}$ The authors hypothesised that the physical presence of the foreskin may mask the symptoms (typically milder than gonorrhoea) of NGU. The difference from our study could be explained, at least in part, by the fact that our study group had a much lower threshold for seeking medical attention. The majority (table 1) were asymptomatic and had presented for STD screening.

A recent South Australian study found that uncircumcised men were independently at increased risk of current diagnoses of both chlamydial and gonococcal infection (odds ratios of 1.3 and $2 \cdot 1$ respectively) on multivariate analysis factoring in "multiple partners" in the previous month. ${ }^{14}$ However, in a separate report on the same sample, ${ }^{15}$ being uncircumcised was also a risk factor for pediculosis pubis (OR 1.5) -a notion that lacks plausibility. In the latter report, ${ }^{15}$ being uncircumcised was protective for genital warts and had no significant effect on the risk of genital herpes.

Only about $3 \%$ of the Australian male population would have religious reasons for circumcision. British workers have speculated that only another $1-2 \%$ would have unequivocal medical reasons for circumcision later in childhood, usually balanitis xerotica obliterans (leading to true phimosis) and possibly recurrent balanoposthitis. ${ }^{16}$ Much of the public rhetoric in Australia ("We don't cut babies' ears off because they need to wash behind them") is opposed to neonatal circumcision and a health service study had indicated that 
circumcision had become less common in Australia by $1983 .{ }^{17}$ Thus we were surprised to find that $62 \%$ of our study population was circumcised and that younger men were just as likely to be circumcised as older men. A comparable overall circumcision $(63 \%)$ rate has been reported from a South Australian STD clinic, ${ }^{18}$ though in that clinic younger men were slightly less likely $(55 \%)$ to have been circumcised. Some British authors have deplored circumcision rates in that country of $7 \%$ and describe the majority of these procedures as "unnecessary". ${ }^{16}$ As Australia enjoys close cultural links with Britain these dramatically different male circumcision rates imply that cultural determinants of the procedure are amenable to the influence of the "medical gatekeepers". Notably, Australia has a largely fee-for-service system of payment for health services.

While the universally negative findings of the current study should contribute to the current debate on the need for male circumcision, they cannot be automatically extended to developing societies. In other settings, other STDs may be more prevalent and access to medical services or running water may significantly alter the relationship between circumcision and STDs including HIV infection. ${ }^{319}$ Care should also be taken to ensure that circumcision status is not a surrogate marker of culturally-determined risk or health-care seeking behaviour.

This work were supported by a Commonwealth AIDS Research Grant. Our thanks to Professor Tony Cunningham, Peter Field and David Ho of the Virology Unit, Centre for Infectious Diseases and Clinical Microbiology, Westmead Hospital for performing serological tests for HSV.
1 Parker SW, Stewart AJ, Wren MN, Gollow MM, Straton JAY. Circumcision and sexually transmissible disease. Med f Aust 1983;2:288-90.

2 Taylor PK, Rodin P. Herpes genitalis and circumcision. Taylor PK, Rodin P. Herpes gen
Br $\mathcal{F}$ Venereal Dis 1975;51:274-7.

3 Jessamine PG, Plummer FA, Ndinya Achola JO, et al. Human immunodeficiency virus, genital ulcers and the male foreskin: synergism in HIV-1 transmission. Scand $\mathcal{F}$ Infect Dis 1990; Suppl 69:181-6.

4 American Academy of Pediatrics: report of the Task Force on Circumcision. Pediatrics 1989;84:388-91.

5 Davidson F. Yeasts and circumcision in the male. $B r f$ Venereal Dis 1977;53:121-2.

6 McDonald AM, Whyte BM, Jacobs D, et al. Voluntary HIV antibody testing among STD clinic patients: a pilot study. Med F Aust 1990;153:12-4.

7 Ho DWT, Field PR, Sjögren-Jansson E, Jeansson S, Cunningham AL. Indirect ELISA for the detection of $\mathrm{HSV}-2$ specific IgG and IgM antibodies with glycoprotein G (gG-2). $f$ Virul Methods 1992;36: glycopro $249-64$.

8 Bassett I, Donovan B, Bodsworth NJ, et al. Herpes simplex virus type 2 infection of heterosexual men attending a sexual health centre. Med $\mathcal{F}$ Aust 1994;160:69-70.

9 Wilson RA. Circumcision and venereal disease. Can Med Assoc $\mathcal{F}$ 1947;56:54-6.

10 Oriel JD. Natural history of genital warts. $\mathrm{Br} F$ Venereal Dis 1971;47:1-13

11 Cook LS, Koutsky LA, Holmes KK. Circumcision and sexually transmitted diseases. Am $\mathcal{f}$ Public Health. 1994;84:197-201.

12 Cook LS, Koutsky LA, Holmes KK. Clinical presentation of genital warts among circumcised and uncircumcised heterosexual men attending an urban STD clinic. Genitourin Med 1993;69:262-4.

13 Smith GL, Greenup R, Takafuji ET. Circumcision as a risk factor for urethritis in racial groups. Am $\mathcal{F}$ Public Health 1987;77:452-4.

14 Hart G. Factors associated with genital chlamydial and gonococcal infection in males. Genitourin Med 1993;69: 393-6.

15 Hart G. Venereologica: Facts and Figures from an STD Clinic. Adelaide, South Australian Health Commission. 1993:38.

16 Gard A, Collin J. Save the normal foreskin: Widespread confusion over what the medical indications for circumcision are. $B M \mathcal{F}$ 1993;306:1-2.

17 Wirth JL. Circumcision in Australia: An update. Aust Paediatr $\mathcal{F}$ 1986;22:225-6.

18 Hart G. Venereologica: Facts and Figures from an STD Clinic. Adelaide, South Australian Health Commission, 1992:33.

19 O'Farrell $\mathrm{N}$. Soap and water prophylaxis for limiting genital ulcer disease and HIV-1 infection in men in
sub-Saharan Africa. Genitourin Med 1993;69: 297-300. 